\title{
O Simbólico em Construções: estudando a Vila Barrageira da Usina Hidrelétrica (UHE) Engenheiro Sérgio Motta à luz de Pierre Bourdieu
}

\author{
The Symbolic in Constructions: studying the Hydroelectric \\ Engenheiro Sérgio Motta's Village Dam in the light of Pierre
}

Bourdieu

\author{
Elisângela Domingues Michelatto Natt \\ Doutoranda em Administração pela Universidade Federal de Minas Gerais. Avenida Antônio Carlos, 6627, Pampulha - Belo Horizonte \\ -MG. E-mail: elisdomingues@gmail.com
}

Elisa Yoshie Ichikawa

Professora do Departamento de Administração da Universidade Estadual de Maringá. Avenida Colombo, 5790, Maringá - PR.

E-mail: eyichikawa@uem.br

\section{Resumo}

Este trabalho tem por objetivo discutir aspectos simbólicos da construção e da estruturação da Vila Barrageira de Primavera. Para Bourdieu, determinações materiais e simbólicas agem sobre estruturas sociais e psicológicas, por uma relação complexa de interdependência. No caso estudado, os dados mostram que ao projetar a vila, a Companhia Elétrica de São Paulo (CESP) explicitou o fato de que realidades diferentes existem e são reconhecidas coletivamente. A classificação dos agentes, como aconteceu na projeção da vila, representa o conceito distributivo de que os agentes se fazem a partir de uma prescrição que é velada, porque é universalmente aceita e admitida como fatídica.

Palavras-chave: Usina Hidrelétrica. Vila Barrageira. Simbolismo.

\section{Abstract}

This paperaims to arguethe symbolic aspectsof construction andstructuringof the Primavera Village Dam. For Bourdieu, material and symbolic determinations, act onsocial and psychological structures, by acomplex relationshipof interdependence. In the studied case, the data showed that in project the village, Electric Company of São Paulo explicited the fact that it there a different realities, and are collectively acknowledged. The agents classifications, as occurred in the designing of the village,represents the classificatory concepts of the agents made from veiled prescription, because it is universally accepted and admitted as that fateful.

Key word: Hydroelectric Plant. Village Dam. Symbolism. 


\section{INTRODUÇÃo}

No percurso para a busca e o aprimoramento da geração de energia elétrica, a humanidade percorreu um longo caminho, permeado por significativas transformações e muito dispêndio de tecnologia e recursos humanos e ambientais. Foi a partir da emergência da industrialização, experimentada pelo Brasil, principalmente na década de 1960, que se promoveu a obtenção da super e da infraestrutura, por meio de construções gigantescas, dentre as quais se encontram as hidrelétricas. Essas construções eram parte de um projeto que visava à consolidação das indústrias de base para implementação do modelo capitalista de integração ao mercado internacional. Foi um período de implantação e de expansão da industrialização que marcou a reorganização do espaço brasileiro em relação às questões socioambientais.

Sob a égide de um discurso progressista, de intencionalidade mercantil e, portanto, simbólica, as hidrelétricas trazem, em princípio, uma esperança de crescimento. Conforme discute Santos (2006), a promessa econômica e o progresso são características de um processo que envolve símbolos capazes de permitir a aceitação da racionalidade do objeto em questão, mas que numa realidade clara e objetiva, pode também vir para dispersar a relação humana com o ambiente, impondo muitas vezes, relações desiguais. Esses aspectos simbólicos, tais como a promessa de prosperidade e a esperança incutida nas pessoas, que passam a crer que uma industrialização desenfreada trará sucesso, são intrínsecos à intencionalidade mercantil.

Atrelada às promessas de progresso, as hidrelétricas abarcam em seu empreendimento uma série de outros importantes aspectos fundamentais à transformação do meio em que serão inseridas. Pequenas vilas são organizadas para a moradia daqueles que trabalham na construção da hidrelétrica. Muitas vezes, essas vilas se estabelecem como pequenos distritos, chegando à condição de município em algumas situações. Para Bortoleto (2001), a mudança na estrutura urbana se deve ao grande número de pessoas atraídas pela intensificação no fluxo de capital nas regiões onde se estabelecem as hidrelétricas. Essa mudança, no entanto, não é isenta de trazer, em seu conjunto, uma série de aspectos simbólicos que podem alterar a dinâmica local.
A abordagem dos elementos simbólicos está geralmente ligada às questões que envolvem aspectos reais e imaginários, o que faz desse tema algo de grande complexidade. Conforme Faria (2007), é preciso compreender, no entanto, que os símbolos se constituem como uma forma por meio da qual uma ideia e sentimento, que podem estar no inconsciente e que possuem significação, são representados de maneira consciente. Para o autor, a unidade mínima do simbólico é o significante, que tem como característica o fato de não comparecer isolado, pois está sempre articulado com outros significantes.

No intuito de desvelar esses significantes, Bourdieu (2008c) explorou pautas de análises mediadas por elementos ativos identificáveis, tanto em suas classes quanto em suas classificações, ou seja, explorou não apenas a classe a qual pertencem tais elementos, mas também a maneira de classificá-los. O autor investiu na transcrição linguística para evidenciar teores de confrontos sociais, políticos e simbólicos, eminentes nas lutas classificatórias, essas lutas capazes de enquadrar as coisas e os indivíduos sob as determinadas denominações. Seu objetivo era extrair uma escuta expressiva e reveladora dos embates em condições de mobilização dos interesses materiais e simbólicos decisivos aos grupos investigados.

Castoriadis (1982 apud FARIA, 2007) aponta que embora o simbólico se encontre primeiramente na linguagem, ele também está presente nas instituições. No mundo social-histórico, todas as coisas estão entrelaçadas com o simbólico, de forma indissociável. As atitudes, os indivíduos e os produtos, são elementos que existem dentro de uma rede simbólica, com sistemas que visam ligar os significados aos símbolos. Estas ligações ganham validade de tal maneira que se tornam relativamente forçosas para a sociedade ou para os grupos envolvidos.

Para Bourdieu (2004), esses grupos sociais podem ser analisados sob a perspectiva da Teoria dos Campos. Sua teoria, além de permitir a observação e a análise estrutural dos grupos sociais, que ele define como campo de lutas e de conflitos, também, trouxe ao universo das análises sociológicas conceitos muito valiosos como agente e habitus.

De acordo com o autor, a estrutura dos campos é definida conforme a disponibilidade e distribuição de capitais que os agentes possuem. Esses capitais 
podem ser econômico, cultural, social ou simbólico. De acordo com a distribuição e o volume do capital que os agentes possuem é que ocorre a sua caracterização. Esses agentes, por sua vez, determinam a estrutura do campo com intensidade proporcional ao seu peso, que é dependente do peso de todos os outros agentes inseridos no campo. Assim, todo o espaço exerce pressão sobre os agentes, e essa pressão da estrutura é mais sentida por eles, quanto mais frágil for o seu peso em relação aos demais. Essa forma de imposição não ocorre, necessariamente, de forma direta, mas afeta todos os envolvidos no campo, propiciando o surgimento do habitus, ou seja, a aquisição de sistemas adquiridos que funcionam no nível prático como princípios de classificação e simultaneamente como princípios organizadores da ação.

Considerando a dinâmica dos campos e os impactos causados a partir dos empreendimentos hidrelétricos no Brasil, se faz interessante a análise do simbolismo envolvendo as vilas surgidas a partir desses projetos. Dentre todos os elementos que se pode levantar a partir do contexto dos grandes empreendimentos hidrelétricos, optou-se, no presente artigo, por abordar o simbolismo presente nas construções prediais do distrito de Primavera - SP, antiga vila barrageira de Porto Primavera. Dessa forma, este trabalho tem por objetivo discutir os aspectos simbólicos da construção e da estruturação da Vila Barrageira de Primavera, a partir da fundamentação de Pierre Bourdieu.

Para tanto, serão apresentados alguns elementos considerados importantes para a adequada compreensão do que se considerou para a análise que segue, como algumas considerações sobre simbolismo, sobre a construção da Usina Hidrelétrica Engenheiro Sérgio Motta, e a caracterização do objeto de investigação, o distrito de Primavera - SP.

\section{Bourdieu e as Formas Universais do Simbolismo}

A necessidade de se explorar o tema simbolismo é para que se tenha a adequada dimensão do que foi considerado para a análise do campo. Dessa forma, faz-se importante retomar alguns aspectos sobre as formas universais do simbolismo. Conforme discorre Sperber (1974), o estudo do simbolismo permite que se investigue, em nível particular, algo que pode ser aplicável a diferentes situações. Para o autor, essas formas universais apresentam condições e focalização universais, no entanto, os campos de evocação que são determinados por essa focalização costumam divergir de uma sociedade para a outra, de acordo com o ponto de vista particular que se adota em cada uma delas. Em outras palavras, eles possuem uma estrutura focal universal, mas um campo de evocação variável.

A análise a partir da Teoria dos Campos permite observar que o ajustamento a uma determinada demanda não é o produto de uma busca consciente, mas o resultado de uma correspondência estrutural. As marcas são como distintivos, produzem a existência em um universo onde existir é diferir, e ao mesmo tempo, ser próprio ou comum a um mesmo grupo. Um costureiro, por exemplo, não veste clientes, mas subjetividades e as inquietações, ternuras e ansiedades de uma massa de homens e mulheres. Como sugere Bourdieu (2008a), o valor distintivo de um produto é relacional à estrutura do campo na qual ele se difere, $e$ os valores duradouros são aqueles que podem colocar a seu serviço instituições capazes de assegurar, de forma duradoura, um mercado econômico ou simbólico, produzindo concorrência para a apropriação com todos os lucros materiais e simbólicos que assegura.

Segundo Bourdieu (2008c), os ritos e as representações permitem observar modalidades complementares de fabricação do simbólico, demonstrando-se capazes de exprimir demandas diversificadas dos agentes, reprocessando suas experiências e transfigurando-as, dando margem a eventuais transformações.

Para Eaton (1925, apud SANTOS, 2006) todo símbolo equivale a si mesmo e pode substituir ao seu conteúdo originário de forma completa, em qualquer contexto, sem que haja alteração de sentido. Para o autor, cada símbolo pode ter apenas um sentido, o que não implica dizer que os símbolos não adotam as características atribuídas pelos agentes que os evocam, mas sim que, na essência, os valores e significações são unívocos. Santos (2006) discorre que a sociedade, ao passar por movimentos de cisão, tem seus símbolos destacados, se soltando de tal forma que, num movimento geral, continua a ser o mesmo de quando tudo iniciou; ou seja, ao se desprender do contexto atual, os símbolos voltam a ter as características que possuíam no início do processo que estruturou esse contexto. 
Sperber (1974), ao descrever as possibilidades de percepção do que vem a ser uma raposa, traz um exemplo muito simples dos significados e dos atributos com os quais categorizam-se as coisas ou as pessoas que, independentemente desses significados, continuam sendo elas mesmas. Para ele, o valor da raposa não está na palavra que a nomeia, mas em tudo de simbólico que a palavra carrega e representa, em tudo o que se acredita saber sobre as raposas.

Nesse sentido, Bourdieu (2009a) percebeu os sistemas simbólicos como instrumentos de conhecimento e de comunicação, que apenas podem exercer um poder estruturante porque são estruturados e distinguem-se fundamentalmente conforme são produzidos e ao mesmo tempo apropriados pelo grupo ou agente. São produzidos por um corpo de especialistas, num campo de produção e de circulação relativamente autônomo. Os sistemas simbólicos devem sua força ao fato de que as relações que se exprimem neles só se manifestam em forma desconhecida de relações e de sentido.

A diferença socialmente conhecida e reconhecida só existe para alguém capaz de perceber as diferenças e, também, de reconhecê-las como significantes, interessantes, um sujeito dotado de aptidões e da inclinação para fazer as diferenças que são vistas como significativas no universo social considerado. A distinção é uma diferença inscrita na própria estrutura do espaço social quando percebida segundo categorias da apropriação e de estrutura. Seguindo o raciocínio de Bourdieu (2009a), pode-se afirmar que o capital simbólico é um capital de qualquer espécie que, quando percebido por um agente dotado de categorias de percepção resultantes da incorporação da estrutura de sua distribuição, o conhece e reconhece como algo óbvio.

Bourdieu (2009b) traz uma visão que privilegia as funções sociais pelos sistemas simbólicos que tendem a se transformar em funções políticas, na medida em que a função lógica de ordenação do mundo subordina-se às funções socialmente diferenciadas de diferenciação social e de legitimação das diferenças. Nesse sentido, a cultura só existe sob a forma de símbolos, por um conjunto de significados dos quais provém sua eficácia, em que a percepção dessa realidade seduz e inculca de forma indissociável de sua função política. E não existindo puras relações de força, não há também relações de sentido que não estejam referidas e determinadas por um sistema de dominação.
De acordo com Bourdieu (2009a), as representações geradas segundo esquemas adequados às estruturas do mundo do qual são produto, possuem o efeito de consagrar a ordem estabelecida. E a lógica de defesa é a mesma para todos os corpos, cuja permanência no privilégio depende da sua capacidade de manter o controle sobre os mecanismos apropriados a assumir a sua reprodução, quer dizer, a reconhecer, no duplo sentido de marcar e de consagrar os membros legítimos do corpo.

De acordo com Bourdieu (2008a), as determinações materiais e simbólicas agem sobre as estruturas sociais e psicológicas dos agentes, por uma relação complexa de interdependência. Nas práticas disciplinares, valores culturais são transmitidos. É no domínio da produção simbólica que se faz sentir a influência do Estado, em que as administrações públicas e seus representantes são os grandes produtores de problemas sociais que a ciência social frequentemente apenas autentica, retomando-os por sua conta como problemas sociológicos. É assim que se instala progressivamente uma lógica econômica específica, fundada sobre impostos sem contrapartida e em seguida na redistribuição que funciona como princípio de transformação do capital econômico em capital simbólico.

Para Bourdieu (2008a), o capital simbólico é uma propriedade qualquer, podendo se apresentar em muitas formas, físicas, econômicas, culturais e sociais, percebidas pelos agentes por meio de categorias de percepção que lhes permite percebê-las e reconhecê-las, atribuindo-lhes um valor. Trata-se de uma forma de capital cognitivo, apropriado sobre o conhecimento e o reconhecimento. O eufemismo é o que permite dizer tudo, sem dizer o que não se diz, permitindo nomear o inominável, em uma economia de bens simbólicos onde o econômico, no sentido usual, funciona como uma espécie de toma lá dá cá.

É algo que se constitui como uma propriedade que, ao ser percebida, conhecida e reconhecida pelos agentes, torna-se simbolicamente eficiente, como uma força mágica, uma propriedade que responde às expectativas coletivas e, portanto, exerce uma espécie de ação à distância, sem qualquer contato físico. É um capital que pressupõe a existência de agentes sociais constituídos, em seus modos de pensar, de tal forma que conheçam e reconheçam o que lhes é propos- 
to, crendo e rendendo-lhe obediência e submissão. (BOURDIEU, 2008a)

É importante a compreensão de que as produções simbólicas estão comumente relacionadas aos interesses das classes dominantes, conforme assinala Bourdieu (2009a). Segundo o autor, diferentes classes ou frações de classes, estão envolvidas em uma luta simbólica, que visa à imposição de uma definição do mundo social de acordo com os próprios interesses. Dessa forma, é realizada a imposição do campo das tomadas de posições ideológicas, que reproduz de forma transfigurada, o campo das posições sociais.

Bourdieu (2009a) afirma que o campo de produção simbólica é como um microcosmo da luta simbólica entre as classes. Para ele, os produtores, ao servirem os seus interesses na luta interna do campo de produção, servem aos interesses dos grupos exteriores ao campo. Esses grupos exteriores, por sua vez, buscam legitimar sua dominação por meio da própria produção simbólica, que na essência, só servem verdadeiramente aos interesses dos dominantes. Conforme o autor, os sistemas simbólicos se fortalecem por meio das relações de força que são exprimidas neles, embora se manifestem em formas irreconhecíveis, fazendo com que as reproduções simbólicas sejam as mais eficazes, contundentes e permanentes formas de exercício da dominação.

Por meio do simbólico, a sociedade vai tomando forma, e ao mesmo tempo, permite aos agentes transferirem seus valores e crenças aos agentes de outras épocas ou outros campos. Nesse sentido, vilas barrageiras podem mostrar como certos valores e crenças estruturam $e$ ao mesmo tempo são estruturados, a partir de inculcações da disposição física da sua estrutura. É sobre isso que este trabalho pretende discutir.

\section{Percurso Metodológico da InVESTIGAÇÃo}

Este artigo é uma pequena parte de um projeto de investigação que trata dos aspectos simbólicos e dos impactos das construções de usinas hidrelétricas. Este é um recorte muito particular dessa pesquisa maior. A fim de poder selecionar os elementos importantes para o presente trabalho, alguns passos foram realizados. Para familiarizar-se com o campo, foram realizadas visitas ao distrito de Primavera, que se localiza no estado de São Paulo. Foi o momento de conhecer um pouco o lugar, sua aparência, o comportamento visível das pessoas que habitam no local, bem como alguns costumes ou mesmo serviços oferecidos. Ao todo foram realizadas quatro visitas.

Durante essas visitas se conversou com algumas pessoas. Foram conversas informais, mas que nos levaram a conhecer um pouco do caminho que deveria ser percorrido em busca de esclarecimentos sobre o campo. As pessoas pareceram se orgulhar da beleza que o lugar apresenta, mas ao mesmo tempo se demonstraram envergonhadas ao relatar os abusos políticos e desmandos de alguns proprietários de terras na região. Esse foi o ponto que nos levou posteriormente à investigação da história que resultou no levantamento de informações que nos situaram no processo de estruturação inicial do campo. Foram as visitas que mostraram a importância em conhecer mais a respeito do campo, e a partir dessa modificação do ponto de vista, foi possível evitar um olhar que nos limitasse em relação aos principais pontos críticos constituintes do campo.

A partir da necessidade de retratar a história anterior ao campo, fomos à busca de elementos que pudessem revelar a dinâmica que envolveu os agentes e os levou ao entendimento e construção do campo tal como ele é. Foi realizado um levantamento de materiais que pudessem contar um pouco a respeito da região. Não foram muitos os registros encontrados que relatavam os conflitos com riqueza de detalhes. Foram buscados documentos, jornais, livros, artigos e tudo o que pudesse revelar conteúdos relativos ao campo.

Com a escassez de material a respeito da história da região que abarca o campo, foi necessário recorrer, além de artigos científicos, a materiais alternativos, como jornais, revistas, trabalhos de conclusão de curso, dissertações e teses realizadas a partir de investigações na região. Esse material foi analisado sob a perspectiva de delinear o processo de constituição do campo, bem como o próprio campo.

Quanto mais se lia sobre Primavera e a região ao entorno, mais se percebia a necessidade de buscar mais informações. E nessa busca encontrou-se um trabalho de conclusão de curso que nos disse muito a respeito de importantes moradores do distrito. Trata-se de um trabalho que revela um pouco das tradições e costu- 
mes dos agentes inseridos no campo e denominados barrageiros. Esse trabalho nos fez ir à busca de fatos que pudessem retratar a história de origem da vila barrageira que mais tarde se tornou Distrito.

Ao tentar entender a constituição e distinção dos agentes no campo recorremos a trabalhos de arquitetura que nos revelaram importantes elementos que, como percebemos, foram cruciais para o processo de constituição das estruturas e da percepção e ação dos agentes. O livro de Tsukumo (1994) nos forneceu imagens que foram fundamentais para a adequada compreensão do campo e das formas de intimidação e distinção entre os agentes. Os trabalhos de Vianna (2004; 2006a; 2006b) completaram as informações obtidas em Tsukumo (1994), pois retratavam não apenas as condições da estrutura física que demarcava o campo, como também trouxe informações referentes aos modos de vida e alguns costumes dos agentes, principalmente os agentes dominados. Ao utilizarmos esses materiais, nos apoiamos na afirmação de Santos (2000), de que a pesquisa documental pode ser realizada em fontes como relatórios, cartas, pareceres, fotografias e obras originais de qualquer natureza.

Assim, a coleta de dados foi realizada por meio de pesquisas documentais e observação. Em primeiro lugar, como descrito anteriormente, foram feitas visitas informais ao Distrito para as observações. Em seguida realizou-se a investigação acerca da história do campo, por meio da leitura de jornais, processos judiciais, diário oficial, revistas de circulação livre e científicas, livros, trabalhos acadêmicos, fotografias, plantas baixas do núcleo residencial Primavera e também de algumas das construções que compõe o núcleo e outros. Esses documentos, em forma de materiais escritos e, também, em forma de figuras e de imagens, foram a fonte de informação sobre o campo.

Essa investigação documental se constituiu como uma técnica valiosa, pois possibilitou o desvelar de aspectos incisivos ao tema do presente trabalho, o que de acordo com Lüdke e André (1986) se deve ao fato de se tratar de uma técnica que busca identificar as informações factuais nos documentos a partir de questões ou hipóteses de interesse para a pesquisa.

A utilização da planta baixa do núcleo Primavera, bem como das plantas das casas foram importantes porque segundo Bourdieu (2008a), a distribuição de uma sociedade em classes a qualifica por sua relação com a distribuição no espaço das classes e frações de classe, bem como suas propriedades, terras ou imóveis. E essas distribuições espaciais dos diferentes campos tendem a sobrepor-se, e a representação cartográfica da distribuição no espaço de uma classe de agentes e instituições constitui uma técnica de objetivação poderosa, desde que se saiba ler na planta a relação construída entre a estrutura do sistema das posições constitutivas do espaço de um campo e a estrutura do espaço social, definido pela relação entre bens distribuídos no espaço e agentes definidos por capacidades desiguais de apropriação de tais bens.

A análise documental, conforme assinala Corsetti (2006), é um passo de suma importância para a pesquisa qualitativa, pois é por meio dessa análise que grande parte das informações é desvelada. De acordo com a autora, as fontes escritas e mesmo as fontes não escritas, costumam alicerçar o trabalho de investigação. Nesse sentido, Bourdieu (2009a) propõe que o analista deve procurar a intenção objetiva escondida atrás da intenção declarada, o "querer dizer" que é denunciado no que ela declara. Para ele, é o analista quem supõe o enunciado de um sentido profundo, de uma pulsão expressiva, biológica ou social que a alquimia da forma imposta pela necessidade social do campo tende a fazer como irreconhecível, obrigando tal pulsão a negar-se e ao mesmo tempo universalizar-se.

Sob essa perspectiva de Bourdieu (2009a), a análise do presente trabalho buscou desvelar aquilo que estava subentendido no material coletado. $\mathrm{Ou}$ seja, nenhum material revelava declaradamente o que propúnhamos a conhecer, mas ao olhar atentamente para o material, foi possível estabelecer os elementos que eram importantes ao entendimento do campo.

\section{A Construção da Usina Hidrelétrica (UHE) Engenheiro Sérgio Motta}

A construção da Usina Hidrelétrica (UHE) Engenheiro Sérgio Motta possibilitou o surgimento de um campo permeado por símbolos, portanto, se faz importante conhecer um pouco sobre esse processo que teve seu início na década de 1970. Segundo Scarpinella (1999), o empreendimento fazia parte dos projetos de expansão industrial no Brasil, idealizados por governos militares durante o período de 1964 a 
1984. Essa expansão requeria o aumento significativo das fontes de energia, daí a proposta para a construção de tantas usinas. Processo que se intensificou nos estados do Paraná e de São Paulo.

A UHE Sérgio Motta está localizada no rio Paraná, ao extremo Oeste do Estado de São Paulo, entre os municípios de Rosana, em São Paulo, e o de Nova Andradina, em Mato Grosso do Sul, no distrito de Primavera. Tudo o que envolve essa obra é grandioso. Trata-se da segunda maior usina da Companhia Elétrica de São Paulo (CESP). Sua barragem é a mais extensa do Brasil. De acordo com Bermann (2007), sua construção esteve envolta em uma rede de empresas como empreiteiras de grandes obras públicas, ligadas a empreendimentos hidrelétricos e que ao longo do projeto estavam acompanhadas por superfaturamentos e muitas irregularidades identificadas, mas nunca apuradas.

Lima (2007) e Gonçalves (1997) apontam que a construção do reservatório de Porto Primavera alterou o ambiente antrópico e o ambiente biótico da região, transformando um trecho do rio Paraná em lago e, consequentemente, modificando seu ritmo e curso normal. Para que fosse possível a construção da usina houve significativa mudança na demografia da região de locação. Como é comum aos megaempreendimentos, pessoas foram realocadas e uma vila operária foi construída para abrigar os operários vindos das mais variadas regiões do Brasil.

Segundo Trevisan (1999), a década de 1990 viu emergir os primeiros processos na tentativa de impedir o enchimento do reservatório, pois os ambientalistas queriam evitar o desastre ecológico que a inundação poderia causar. Documentos e processos judiciais sugerem que a CESP, a partir da tentativa de alguns em impedirem a inundação, passa então a intimidar a população. Em 1998 ocorreu o ultimato da Companhia para que a população ribeirinha deixasse o local - era uma tentativa para resolver de uma vez por todas o problema que vinha se arrastando já por vinte anos.

Ao se passarem duas décadas, a usina finalmente efetivou suas atividades e, como consequência disso, ocorreram alterações nos meios e modos de vida, como a desagregação social de comunidades locais. Houve o deslocamento compulsório da população, a desestruturação das atividades econômicas e dos mercados de trabalho e de terras e a ruptura das teias de relações sociais, entre outros. Honorato (2008) mostra que os impactos foram muito maiores do que os discutidos pelas autoridades e pela imprensa, pois atrelado aos grandes impactos ambientais estavam a perda de identidade social, de sentimento comunitário, as mudanças nas interações sociais cotidianas, as transformações no estilo de vida, a perda de técnicas e matéria-prima da economia artesanal, a perda de marcos históricos, de valores e sentimentos referidos a lugares, o esvaziamento da população da área inundada, a alteração do padrão da população urbana e rural, os movimentos migratórios, as pressões sobre a infraestrutura de educação, preservação, lazer, saúde, saneamento e segurança pública e, ainda, significativos problemas sociais como a prostituição, a gravidez precoce e o alcoolismo.

\section{Símbolos Compartilhados na Construção do Distrito de Primavera}

Em meio a esse cenário é construído o Núcleo Habitacional Primavera, que mais tarde viria a se tornar um distrito do município de Rosana. A região que abriga o distrito de Primavera se desenvolveu em meio a uma sociedade dominada por grileiros de terra, latifundiários, pecuaristas e grandes empresas de construção civil que atuaram na construção de hidrelétricas como a de Rosana e Sérgio Motta (THOMAZ, 2009). No auge das obras da UHE Engenheiro Sérgio Motta, cerca de nove mil trabalhadores foram empregados (CAMPANHARO, 2005; SILVA, 2010). Com o objetivo de atender a esse número de operários, foi criado, na década de 1980, o núcleo residencial de Primavera, dando origem à cidade de Primavera, que, em 1998, contava com uma população de 12 mil habitantes, número que reduziu conforme o último censo realizado pelo Instituto Brasileiro de Geografia e Estatística (IBGE, 2010).

O conjunto de trabalhadores, inicialmente absorvido pela empreiteira contratada pela CESP, foi aos poucos sendo excluído a partir do término das obras e, sem emprego, deu início a um processo de empobrecimento e de pauperização. Muitos não tinham para onde ir e passaram a ser os novos sem-terra dos anos de 1980. (THOMAZ, 2009) 
A movimentação em torno das barragens, com início ao final da década de 1970, não coincide com a construção das casas em Porto Primavera, que somente teve os trabalhos iniciados no final dos anos de 1980. Dessa forma, foram dez anos de trabalho sem que houvesse instalações próximas às obras da barragem. Os moradores tinham que improvisar moradias no município de Rosana, bem como em outras cidades da região.

Primavera foi projetada pela Divisão de Arquitetura e Urbanismo da CESP, pelos arquitetos Hélio Pasta, César Galha Lourenço, Nina Maria Tsukumo, Glaycon Motta Melo, Edmilson Tinoco Jr., Maria Manvela e Armando de Donato Filho. O local escolhido para a instalação do núcleo era favorável à sua sobrevivência, se tratando de um ponto em que três estados dividem a fronteira, Paraná, Mato Grosso do Sul e São Paulo. O distrito está vinculado às rodovias que interligam os três estados e localiza-se a uma distância de $50 \mathrm{Km}$ dos núcleos urbanos mais próximos. (CESP, 2000)

A responsável pela implantação do núcleo residencial foi a empresa Camargo Corrêa, empreiteira contratada pela CESP para a realização das obras envolvendo a UHE Engenheiro Sérgio Motta. O núcleo residencial Primavera foi planejado para dispor de vários tipos de residências, a fim de abrigar trabalhadores de todos os níveis. Havia a programação para áreas arborizadas, clubes de lazer, que eram definidos conforme o nível dos funcionários e, também, de locais de atendimento à população que ali iria residir, como escolas, postos de saúde e serviços urbanos em geral. (SILVA, 2010)

Com um pensamento pautado nas características fabris vigentes, a CESP, em 1970, planejou e realizou as obras das usinas hidrelétricas de Rosana e de Porto Primavera, estendendo às suas vilas todas as regras aplicáveis ao mundo do trabalho. As categorias profissionais dos funcionários empregados pela CESP para realizar as obras da UHE Sérgio Motta eram definidas conforme os níveis de profissionalização.

Os níveis eram denominados como N1, N2, N3, N4, N5 e N6, representando, respectivamente os níveis $1,2,3,4,5$ e 6 . O N1 era composto pelos trabalhadores que realizavam trabalhos não especializados, como ajudantes, meio oficiais, auxiliares e serventes. O N2 era o nível composto por funcionários como carpin- teiro, apontador, motorista, cozinheiro, garçom, vigia e pedreiro. No N3 situavam-se os profissionais que atuavam como auxiliar administrativo, fiscal de campo, fiscal de concreto, escrevente e laboratorista. O N4 comportava os profissionais de nível técnico, tais como técnico de construção civil, técnico de solo, encarregados, auxiliares técnicos, topógrafos e desenhistas. O N5 era o nível em que se encontravam apenas os encarregados técnicos e o N6 reunia os profissionais com nível superior, como por exemplo, os engenheiros.

Os clubes eram a Associação Atlética Porto Primavera (APP), destinado aos funcionários do Nível 1 ao Nível 3, e o Rosana Esporte Clube (REC), permitido aos funcionários do Nível 4 ao Nível 6. Alguns dos entrevistados de Silva (2010) se referem aos clubes como o APP ser o clube dos pobres, dos peões; e o REC como o clube dos ricos, com piscina e tudo mais, expressando nessas palavras a noção da diferença estabelecida na divisão entre funcionários conforme os níveis e de acordo com as funções desempenhadas.

Ao analisar essa divisão com base na Teoria dos Campos, percebe-se que um campo é um espaço onde os indivíduos existem, em forma de agentes ou grupo agente, $e$ as instituições ocupam espaços muito semelhantes aos ocupados pelos agentes individuais, semelhantes no sentido relacional de sua posição. Afinal, não se pode jamais se esquecer de que as posições no campo sempre devem ser observadas sob a ótica relacional. Nesse espaço definido como campo, princípios de visão e divisão são distribuídos e estão presentes, como propriedades, em todos os agentes. A forma como os agentes pensam e se relacionam está fundamentada em suas percepções de classe e de pertencimento as classes, não em sentido ideal, mas prático.

No caso de Primavera, a estrutura do campo, ao mesmo tempo objetiva e subjetiva, foi capaz de estabelecer a "verdade" eas relações entre os agentes no campo. A divisão era clara, tanto no projeto de construção da vila quanto na mente dos trabalhadores da usina. Relatos trazidos por Silva (2010) demonstram que os trabalhadores sabiam qual era o seu lugar, ou melhor, eles entendiam qual era o lugar em que deviam permanecer. Até mesmo os restaurantes eram divididos, isto é, havia um restaurante para atender aos N1 e N2, restaurante para atender aos níveis $\mathrm{N} 3$ e N4 e restaurante para atender os níveis N5 e N6. 
Para compreender a dinâmica do campo Primavera, foi imprescindível ter a noção de que os campos são mecanismos que impõem aos agentes, suas necessidades. Aqui se fez importante retomar mais uma vez o fato de que a ordem o campo, não é aquela ordem a qual se está acostumado, mas sim uma ordem necessária à manutenção do campo, que para continuar existindo precisa instaurar e manter relações duradouras de dependência, seja em relação aos bens materiais ou a garantias de sobrevivência e de reconhecimento perante a estrutura.

Dessa forma, os trabalhadores - neste caso chamados de barrageiros - não eram um bloco homogêneo, pois se trata de um grupo que se constitui de membros com diferentes níveis de capital. Essa diferença faz com que mesmo no núcleo em que se encontram esses agentes, haja distinções capazes de promover o poder relacional, ou seja, mesmo entre esses agentes que compõem um grupo entre aparentes pares, há o princípio de divisão, promotor das regras de dominação vigentes no campo.

É importante lembrar que a incidência de poder no campo não é um caminho de mão única, pois mesmo estando em posições privilegiadas, os agentes detentores de poder recebem constantemente algum tipo de influência dos agentes que ocupam posições menos privilegiadas na estrutura.

De acordo com o que orienta Bourdieu (2008b), os campos estruturam-se a partir de um conjunto de sistemas, como o sistema escolar, o cultural, o religioso e o sistema familiar. Tais sistemas perpetuam a separação entre os agentes dotados de quantidades desiguais de capital. As diferentes formas de aptidões que detêm os agentes são indissociáveis da ordem que emana a manutenção das diferenças sociais. $\mathrm{O}$ acesso às formas de capital distintas separam os agentes pelas diferenças essenciais aos processos de dominação por grupos legitimados à dominação.

No caso de agentes como os barrageiros, a profissão nomeada é uma das formas de distinção, e consequentemente, de definição desses agentes na estrutura, tanto em seus aspectos positivos quanto negativos. Essas marcas distintivas distribuem os agentes hierarquicamente e elas apontam, ainda, qual o seu valor perante a estrutura e que posição a estrutura lhe permitirá tomar em relação às posições dos demais agentes no campo.
Especificamente, no caso de Primavera, a peso das profissões deram aos barrageiros delineamentos de possuidores de características pertinentes ao um campo específico, como se entre os barrageiros houvesse todas as características que permeiam o campo, como se existisse um campo dos barrageiros. Nesse campo, havia os mais abastados de títulos e nomeações profissionais, os mais ou menos abastados, os menos abastados e os familiares de todos eles.

Como parte dessa análise e com base nos dados sobre como os barrageiros de Primavera estavam estruturados, procurou-se reaplicar a figura de Bourdieu (2008b) sobre o espaço das posições sociais e estilos de vida.

A Figura 1 traz uma breve demonstração da determinação dos espaços estruturais de possibilidades para os barrageiros conforme o capital que possuem. As limitações impostas pela estrutura do núcleo evidenciam as possibilidades e indicam ainda o limite estabelecido para cada grupo de agente. Essas possibilidades e impossibilidades fundamentaram o habitus que cada grupo de agentes desenvolveu perante o campo, a partir do capital de que dispunham. Nesse contexto, a linha pontilhada demonstra que o grupo de agentes, totalmente excluído de qualquer possibilidade de ascensão à classe mais próxima, é o grupo dos profissionais sem qualificação, seus familiares $e$ descendentes.

Em termos arquitetônicos da Vila Barrageira, é interessante ressaltar que as moradias variavam não apenas de acordo com as categorias funcionais estabelecidas pela CESP, como também pela perenidade das instalações. De modo geral, as construções eram simples, com coberturas em duas águas, seguindo padrões A, B ou C. O melhor nível era definido como padrão $\mathrm{A}$, o nível intermediário era definido como padrão $\mathrm{B}$ e o nível considerado inferior era determinado como padrão $\mathrm{C}$.

Conforme a proposta de Bourdieu (2008b; 2009a), os espaços das posições sociais e dos estilos de vida são relativos entre agentes e grupos. Os tipos de capital - como a titulação profissional ou escolar - podem ser o reflexo de uma regra para a percepção social. No caso dos barrageiros, além da regra implícita, discutida pelo autor, há aqui um novo elemento, pois as regras não necessariamente são implícitas. Muito do poder que permeia a ordem simbólica, quando se 


\begin{tabular}{|c|c|}
\hline \multicolumn{2}{|c|}{$\begin{array}{l}\text { Capital + da Profissão Nomeada } \\
\text { Profissionais Qualificados }\end{array}$} \\
\hline $\begin{array}{l}\text { Engenheiros e demats protissionais com } \\
\text { formaçio de nivel superior }\end{array}$ & $\begin{array}{r}\text { Encarregados e demais profissionals com } \\
\text { formaģẫo de nível técnion }\end{array}$ \\
\hline Freqücntam o mclhor restauranto & Freqüentam o restaumante de nível intermediário \\
\hline $\begin{array}{l}\text { Moradias bem acabadas e com estrutura de bod } \\
\text { qualidade }\end{array}$ & $\begin{array}{r}\text { Moradias também acabadas com cstrutura do } \\
\text { quatidade intermediaria }\end{array}$ \\
\hline $\begin{array}{l}\text { Filhos frequentando escola com boa estrutura e } \\
\text { professorcs mais preparados }\end{array}$ & $\begin{array}{l}\text { entandn a mesma escola que os filhos } \\
\text { dos profissionais de nivel superior }\end{array}$ \\
\hline Frequentavam o REC & Freqüentavam o REC \\
\hline Capital escolar + & Capital escolar - \\
\hline Capital cconốmico & Capital econômico + \\
\hline $\begin{array}{l}\text { Profissionais sem qualquer tipo de qualificaç̃o } \\
\text { Serventes de podreiro } \\
\text { Auxiliares de serviços gerais }\end{array}$ & $\begin{array}{r}\text { Profissionais com o minimo de quahticacăo } \\
\text { Pedreiros } \\
\text { Cozinheiros }\end{array}$ \\
\hline Frequentam o restaurante de nivel inferior & Frequentam o restaurante de nivel intermediano \\
\hline $\begin{array}{l}\text { Moradias mal acabadas ou mesmo inacahadas e } \\
\text { com cstrutura procdria }\end{array}$ & Moradias mal acahadas e com estrutura inferior \\
\hline $\begin{array}{l}\text { Fithos frequentando escolas com estrutura } \\
\text { procária }\end{array}$ & $\begin{array}{l}\text { Fino d froquentando a escola com estrutura } \\
\text { precaria, of frequientando a mesma escola que os } \\
\text { filhos dôs profissionais de nivel superior, mas } \\
\text { segregados do grupo principal }\end{array}$ \\
\hline \multicolumn{2}{|c|}{$\begin{array}{l}\text { Profissionais Năo Qualificados } \\
\text { Capital - da Profissăo Nomeada } \\
\end{array}$} \\
\hline
\end{tabular}

Figura 1: Espaço das posições sociais e estilos de vida dos barrageiros

Fonte: Adaptada de Bourdieu (2008b)
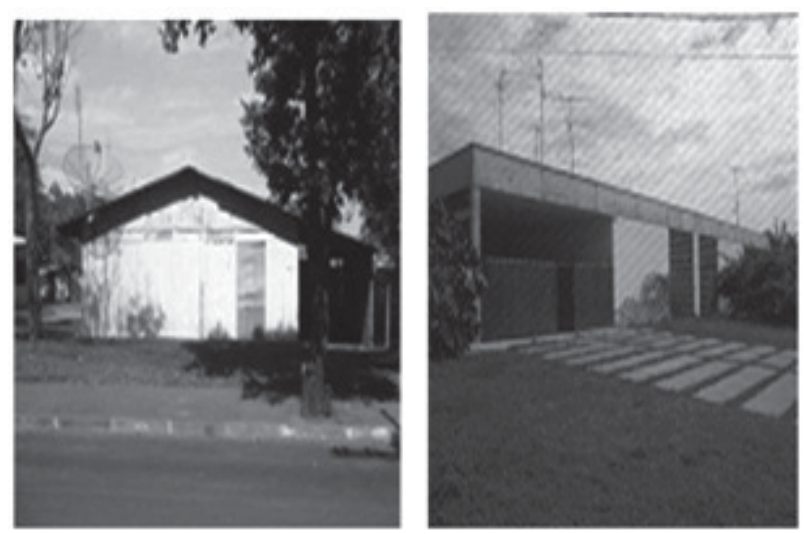

Figura 2: Vista da fachada de uma casa de Nível N1 (Padrão B), à esquerda e de uma casa de Nível N6 (Padrão A), à direita, do núcleo habitacional Primavera

Fonte: Vianna (2006b) 
trata dos barrageiros, é declarado. Esse aspecto não significa, no entanto, que não há nesse elemento nada de simbólico, pois por trás dessa mesma declaração explícita, certamente ainda há formas de dominação que nesse momento nos escapam.

Conforme se observa nas determinações demonstradas no esquema adaptado de Bourdieu (2008b), constatou-se que o campo não é um lugar de posições dispersas. Notou-se que a distribuição no campo se dá de forma organizada e estruturada e, nesse caso específico, de maneira pré-definida. Esses profissionais, com suas histórias próprias, são uma construção de vários outros campos que se perpassam, mas agora estão dispostos em um novo campo, sob as novas condições, para darem a continuidade ao processo de autoestruturação e de estruturação do novo campo.

As relações percebidas, conforme a disposição dos agentes no campo, estão pautadas na estrutura. Isto é, a estrutura definiu quanto vale o capital de que os agentes dispõem e como eles podem se utilizar desse capital. A relação de um indivíduo ou grupo de indivíduos se fundamentou nessa estrutura. Como se percebe na Figura 1, as permissões e as limitações colocadas às categorias profissionais dispostas inicialmente no campo determinam quem terá ou não oportunidades de exercer certo poder no campo.

Até mesmo o material utilizado na construção das residências também se diferenciava conforme a destinação da moradia. Isto é, para os funcionários de nível mais alto, casas construídas com material de me-

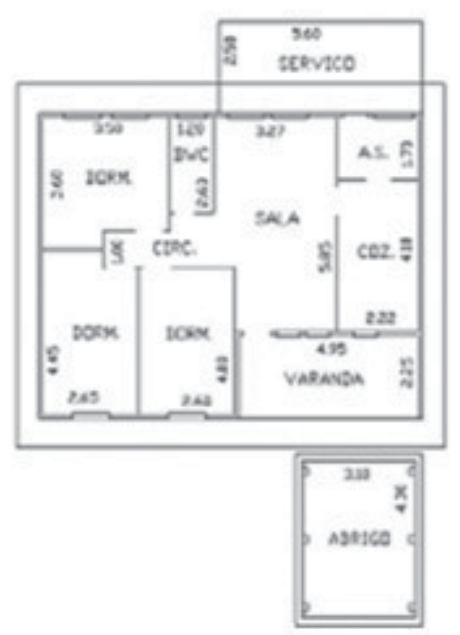

Figura 3: Plantas das moradias de tipo C

Fonte: Tuksumo (1994) lhor qualidade. As plantas apresentavam uma divisão funcional dos ambientes (ver Figuras 3 e 4), em uma tentativa de se emparelhar ao que pedia a arquitetura moderna, mas com referência à velha tripartição burguesa, ou seja, espaço social, de serviço e íntimo. (VIANNA, 2006b)

A segregação sentida tanto na diferença clara entre os tipos de moradia, conforme o nível dos profissionais, também era percebida em relação aos serviços prestados. Vianna (2006b) conta que um dos moradores da cidade de Primavera, instalado ali desde 1982, declarou em entrevista que a diferença entre as famílias de trabalhadores contratados pelas usinas em relação às famílias dos engenheiros da CESP era grande, pois em várias situações era notada a diferença, como por exemplo, nas escolas que, se não fossem separadas em unidades distintas, segregavam as crianças em salas diferentes, reservando as melhores instalações quanto à ventilação e à insolação aos filhos dos engenheiros. Os presentes distribuídos pelos bombeiros na época do Natal, também eram destinados apenas às crianças que pertenciam às famílias dos engenheiros. $\mathrm{E}$, ainda, a qualidade dos clubes e espaços públicos de convivência era radicalmente distinta.

Vale ressaltar que as marcas de distinção, colocadas sobre os agentes no campo, são o que Bourdieu (2009b) chamou de duplicadores simbólicos dos valores de posição vinculados à própria posição na estrutura social. Para o autor, essas marcas servem até mesmo para que os agentes se apropriem de modelos

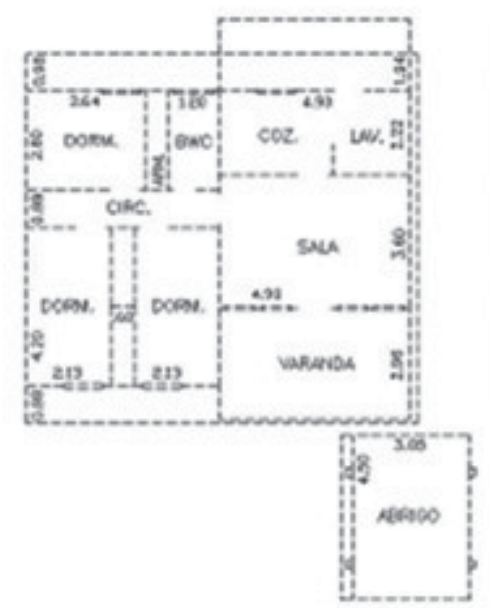




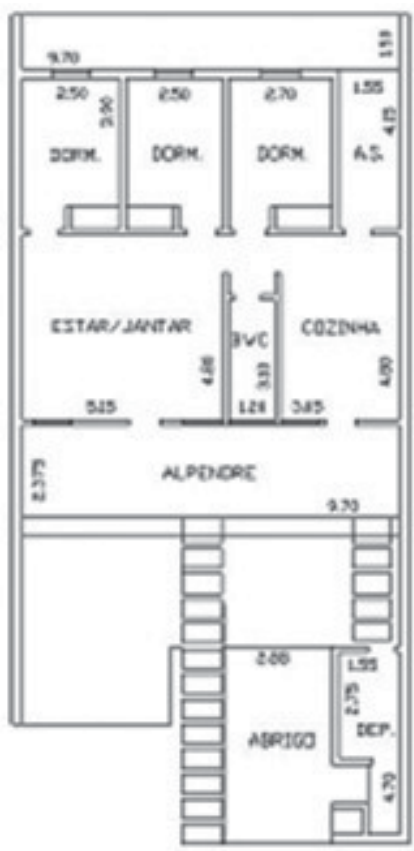

Figura 4: Plantas de moradias do tipo B

Fonte: Tuksumo (1994)

de transmutação das diferentes distinções, obviamente, conforme a estrutura lhe permitir, já que esses modelos dependem da educação dos agentes e das condições perante a estrutura.

Ao projetar o núcleo residencial, a CESP demonstrou o fato de que as realidades sociais existem e são reconhecidas coletivamente. A classificação dos grupos de agentes, como aconteceu na projeção do núcleo, representa o conceito classificatório, mencionado por Bourdieu (2008b), de que os agentes e as classes se fazem a partir de uma prescrição que é velada porque é universalmente aceita e admitida como fatídica.

Em relatos apontados por Silva (2010), trabalhadores e ex-trabalhadores da barragem fizeram referências ao fato de que sempre foram peões, ou seja, de nível baixo. Esses trabalhadores dizem que sempre andavam de ônibus, enquanto os engenheiros andavam de carro ou perua. Assim, as casas e as demais construções em Primavera, eram apenas mais um indicativo de suas condições, de quem eles eram.

Para Vianna (2006a), o núcleo habitacional, junto às usinas de Porto Primavera e Rosana, era estratificado socialmente. Desde o tipo das moradias até as escolas e os clubes para o lazer, tudo era definido conforme as funções desempenhadas pelos funcionários, conforme

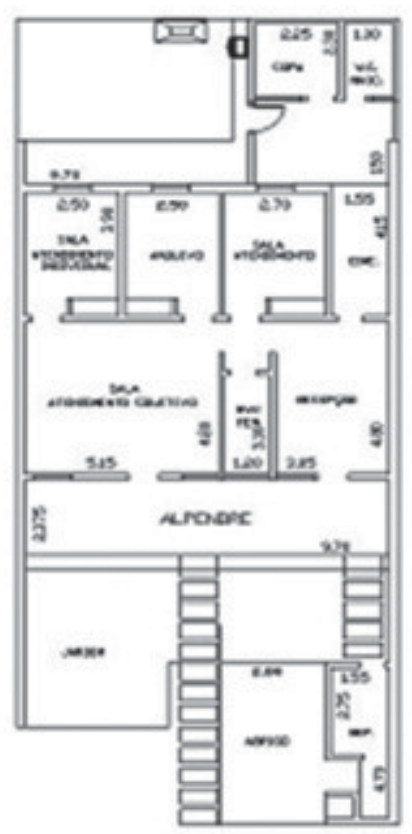

já vimos anteriormente. No entanto, a CESP se declarava como a desenvolvedora de um modelo moderno de cidade aberta, sem influências que ditassem alguma regra específica e, que, ao fim das obras, tornar-se-ia uma cidade independente.

O poder relacional possibilitado pela estrutura da cidade de Primavera deu aos agentes a possibilidade de se prevalecer sobre outro agente no campo, mesmo sem ter um capital significativamente importante fora da estrutura em que se dispõe. No entanto, embora houvesse essa apropriação de certo grau de poder, houve também uma forma de aproximação e união de agentes mais próximos na estrutura. Esses grupos diferentes, mas que ocupam uma posição mais próxima na estrutura, tiveram a possibilidade, inclusive, de se colocar em uma situação de classe e se mobilizar contra outros grupos de agentes mais distantes na estrutura.

Esse aspecto foi percebido quando se observou a alocação nas escolas em Primavera, a separação dos barrageiros em clubes distintos, conforme os níveis dos funcionários. A separação nos restaurantes, e a declaração objetivada na disposição e condições das moradias. As melhores casas, cedidas aos profissionais de níveis mais altos, não apenas eram melhores em condições estruturais e de acabamento, como também 
eram localizadas em áreas mais nobres, como próximas de parques e áreas verdes.

Vianna (2006a) revela que a CESP controlava seus funcionários, tudo era feito conforme os horários estabelecidos pela organização, os turnos de trabalho, a condução da casa em que moravam os trabalhadores até as obras da usina e, ainda o próprio almoço dos funcionários era gerenciado pela empresa. Sempre havia um veículo de plantão, tanto nas instalações da usina quanto nas instalações de moradia. Tudo era feito para que a comunicação entre as residências e a usina fosse rápida. Técnicos e demais funcionários estavam sempre de sobreaviso, visando atender emergências relacionadas à obra.

A disposição dos agentes deu a eles a pretensão de existir como grupo, estabelecendo princípios de visão e de divisão comuns, tornando-se uma referência que os identificasse em relação uns aos outros, tornando-os possuidores de uma visão idêntica de sua unidade. Os símbolos utilizados no campo, como as casas, tinham uma função muito clara no meio social, definir quem era quem e onde cada um deveria estar.

\section{Considerações Finais}

Ao realizar esta investigação, foi possível perceber que as casas diferenciadas, a separação dos grupos e as condições não permitidas a esses ou àqueles agentes revelam a intenção de não permitir que o agente dominado deixe de perceber o seu lugar, a sua posição de dominado naquela estrutura. Essa determinação fez com que o poder se difundisse e se garantisse a partir dos símbolos, pois os barrageiros, cientes de suas condições e de suas limitações no campo, se percebiam em posições que lhes dava uma falsa identidade perante o campo.

É importante atentar-se, devido ao alerta feito por Bourdieu (2008b), de que a representação cartográfica se constitui como uma forte e poderosa técnica de objetivação da distribuição no espaço de uma classe de agentes e instituições. E esse alerta fica muito evidente na observação que se fez nesse trabalho. No caso de Primavera, não apenas a planta nos revela as relações estimadas entre os agentes, como também torna clara a distribuição de bens e agentes e, ainda, as capacidades desiguais de apropriação de capital. Isso se evidenciou na distribuição das crianças em escolas distintas, ou em sua separação nas mesmas escolas, conforme a origem familiar.

Nas relações de força estabelecidas tanto pela estrutura explícita quanto pela estrutura implícita, há aqueles que exercem o poder e aqueles que estão sujeitos a ele, no entanto, todos são agentes, de alguma forma contribuíram para a estrutura. É preciso, porém, esclarecer que não se trata de culpalizar os agentes sujeitos ao poder por acomodarem-se em relação ao campo, mas de sua contribuição dóxica, formadora do habitus que permitiu que cada qual ocupasse sua posição nesse mesmo campo.

Em Primavera se percebeu, com clareza, a noção de espaço proposta por Bourdieu (2008b), de que ele parte do princípio de uma apreensão relacional do mundo social. Uma apreensão pautada no fato de que toda a realidade designada por essa noção reside na exterioridade mútua dos elementos que compõem a própria realidade. Sob esse ponto de vista, os agentes aparentes existem e subsistem na diferença e pela diferença, enquanto ocupam posições relativas em um mundo real.

Esses símbolos firmaram, na vida cotidiana, a estrutura necessária à manutenção do poder. As construções, entre outros símbolos, como as palavras, os modos, as preferências e as limitações, representam muito mais do que o que está aparente. São símbolos fundamentados nos verdadeiros interesses submersos no campo e orquestram a realidade social conforme as orientações dos dominantes. Quando se autonomeiam como barrageiros e criam nomes para práticas que são somente suas, eles assumem a posição de dominados e reconhecem, sem saber, qual é a sua posição no campo.

As famílias, as residências, as atividades profissionais exercidas, $e$ todas as possibilidades ou impossibilidades, prescrevem que posição certos agentes continuarão exercendo dentro da estrutura, geração a geração.

\section{REFERÊNCIAS}

BERMANN, C. Impasses e controvérsias da hidreletricidade. Estudos Avançados, São Paulo, v. 21, n. 59, p. 139-153, 2007. 
BORTOLETO, E. M. A implantação de grandes hidrelétricas: desenvolvimento, discursos e impactos.

Revista Geografares, Vitória, n. 2, jan. p. 56-63, 2001.

BOURDIEU, P. Os usos sociais da ciência: por uma sociologia clínica do campo científico. São Paulo: UNESP, 2004.

BOURDIEU, P. A produção da crença. 3. ed. Porto Alegre: Zouk, 2008a.

BOURDIEU, P. Razões práticas: sobre a teoria da ação. 9. ed. Campinas: Papirus, 2008b.

BOURDIEU, P. A economia das trocas lingüísticas. São Paulo: Edusp, 2008c.

BOURDIEU, P. O poder simbólico. 12. ed. Rio de Janeiro: Bertrand Brasil, 2009a.

BOURDIEU, P. A economia das trocas simbólicas. 6. ed. São Paulo: Perspectiva, 2009b.

CAMPANHARO, L. S. L. O. Impactos socioambientais decorrentes da formação do reservatório da Usina Hidrelétrica Engenheiro Sérgio Motta no Município de Presidente Epitácio. Enciclopédia Biosfera, Goiania, n. 1, p. 1-42, 2005.

CESP - Companhia Energética de São Paulo. Obras do Reservatório da Usina Hidrelétrica Engenheiro Sérgio Motta. São Paulo: CD-ROM, 2000.

CORSETTI, B. Análise documental no contexto da metodologia qualitativa. UNIrevista, São Leopoldo, v. 1, n. 1, p. 32-46, janeiro, 2006.

FARIA, J. H. Poder real e poder simbólico: o mundo das intrigas e tramas nas organizações. In: CARRIERI, A. P.; SARAIVA, L. A. S. Simbolismo organizacional no Brasil. São Paulo: Atlas, 2007.

GONÇALVES, H. C. O processo de implantação da Usina Hidrelétrica de Porto Primavera e seus reflexos na atividade pesqueira e nos modos de vida dos pescadores de Porto XV de Novembro MS. 121f. Dissertação. Presidente Prudente: UNESP, Programa de Pós-Graduação da Faculdade de Ciência e Tecnologia, 1997.
HONORATO, G. A. Gerenciando impactos sócioeconômicos: o papel da Sociologia na implementação de usinas hidrelétricas no Brasil. Revista Espaço Acadêmico, Maringá, n. 86, jun. 2008.

IBGE. Instituto Brasileiro de Geografia e Estatística.

Censo Demográfico. Brasília: IBGE, 2010.

LIMA, L. M. G. A memória submersa e as atividades atuais da população ribeirinha residente em Bataguassu e Presidente Epitácio na Festa Nossa Senhora dos Navegantes. 117f. Trabalho de Conclusão de Curso. Rosana: Departamento de Turismo. Universidade Estadual Paulista Júlio de Mesquita Filho, 2007.

LÜDKE, M.; ANDRÉ, M. E. D. A. Pesquisa em educação: abordagens qualitativas. São Paulo: EPU, 1986.

SANTOS, A. R. Metodologia Científica: a construção do conhecimento. Rio de Janeiro: DP\&A, 2000.

SANTOS, M. A natureza do espaço. São Paulo: EDUSP, 2006.

SILVA, L. F. Reflexos culturais da população do Distrito Primavera expressos no léxico e nos topônimos. 75f. Trabalho de Conclusão de Curso. Rosana: UNESP, 2010.

SPERBER, D. O simbolismo em geral. São Paulo: Cultrix, 1974.

THOMAZ, A. Nova face do conflito pela posse da terra no Pontal do Paranapanema: estratégia de classe entre latifúndio e capital agroindustrial canavieiro. Revista Pegada, Presidente Prudente, v. 10, n. 1, jun. 2009.

TREVISAN, C. Porto Primavera será inaugurada na terça. São Paulo, Folha de São Paulo, São Paulo, publicado em 21 de fevereiro de 1999.

TUKSUMO, N. M. J. Arquitetura na CESP. São Paulo: CESP, 1994.

VIANNA, M. P. Habitação e modos de vida em vilas operárias. São Carlos, USP: Escola de Engenharia de São Carlos, dez. 2004. 
VIANNA, M. P. O desmonte e a conversão dos núcleos residenciais operários construídos pela CESP. São

Paulo, USP, Revista de Pesquisa em Arquitetura e

Urbanismo, São Carlos, v. 4, n. 2 , p. 21-35, 2006a.

VIANNA, M. P. Núcleos Residenciais da CESP: o

processo de desmonte. 356f. Dissertação. São Carlos:

USP, Departamento de Arquitetura e Urbanismo da Escola

de Engenharia de São Carlos, $2006 b$. 